\title{
Use of Evaporative Cooling to Improve 'Rosemarie' and 'Forelle' Pear Fruit Blush Colour and Quality
}

\author{
S.J.E. Wand, W.J. Steyn, D.M. Holcroft, M.J. Mdluli, K. van den Dool and G. Jacobs \\ Department of Horticultural Science \\ University of Stellenbosch \\ Private Bag X1, Matieland 7602 \\ South Africa
}

Keywords: Anthocyanin, heat stress, overhead irrigation, Pyrus communis, sunburn, temperature

\begin{abstract}
In Pyrus communis 'Rosemarie', a potentially lucrative blushed pear cultivar, poor fruit colour has been ascribed to pre-harvest red colour loss during periods of high temperature. High temperatures combined with high irradiances also lead to sunburn on pome fruit. The use of pulsed overhead evaporative cooling (EC) to improve red colour and reduce sunburn in two blushed pear cultivars was evaluated over four seasons (2000/01 to 2003/04) in Stellenbosch, South Africa. 'Rosemarie' fruit blush was usually but not always improved under $\mathrm{EC}$, with a late application (starting two weeks before harvest) yielding the best improvement. Peel anthocyanin concentrations were increased under EC. Incidence of sunburn was reduced during some years, but increased in EC-treated fruit during 2003/04 due to system failure on a hot day. EC initiated early in fruit development initially led to larger fruit with a lower TSS concentration and firmness, but this effect was gradually eliminated following reductions in EC water use. EC had no effect on 'Forelle' pear fruit colour or mass, but reduced firmness and TSS when started early in the season. Sunburn was only recorded in EC-treated fruit during 2002/03 due to system failure on a warm day. Though EC could be used to improve 'Rosemarie' fruit colour in warm production areas, its effect was relatively small compared to colour change in response to fluctuating temperature. The increased risk of sunburn during system 'downtime' highlights the requirement for a highly reliable system.
\end{abstract}

\section{INTRODUCTION}

Insufficient red colour has limited the profitability of blushed pears in the warm production areas of the Western Cape, South Africa (Steyn et al., 2004). Pyrus communis 'Rosemarie', a locally bred early-season cultivar, is especially susceptible to colour loss prior to harvest. This is due to the net degradation of anthocyanin in response to high temperatures (Steyn et al., 2004).

The extent of red pigmentation in fruit peel is primarily determined by light and temperature. High irradiances are a requirement for colour development, but the strong associated radiant heating may be detrimental. Anthocyanin accumulation generally requires low night and moderate day temperatures (Christie et al., 1994; Curry, 1997). High temperatures inhibit the induction and reduce the synthesis of anthocyanin (Curry, 1997; Reay, 1999). They also increase the rate of anthocyanin degradation (Steyn et al., 2004) and thus lead to poor fruit colour.

High summer irradiances and temperatures also give rise to sunburn on exposed fruit surfaces (Bergh et al., 1980). The extent of damage may vary from bleaching to a yellow or bronze discolouration of the skin, and in serious instances to death and browning of the flesh underneath (Schrader et al., 2001). Apple fruit skin temperatures can be up to $8-10^{\circ} \mathrm{C}$ warmer than air temperatures (Bergh et al., 1980; Wiinsche et al., 2001) and sunburn occurs at temperatures of $46^{\circ} \mathrm{C}$ or higher (Schrader et al., 2001). It is not known at which skin temperatures pear fruit experience sunburn.

Overhead evaporative cooling (EC) is used commercially to counteract the adverse effects of high temperature on fruit quality in warm production regions. EC 
reduces peel temperature by up to $8^{\circ} \mathrm{C}$ in apple (Unrath, 1972; Parchomchuk and Meheriuk, 1996; Wiinsche et al., 2001). Improvement in the red colour of apple fruit in response to EC has been reported from several studies (Unrath and Sneed, 1974; Evans et al., 1995; Iglesias et al., 2002). Evaporative cooling also reduced the fading of red colour towards harvest in the red pear cultivar 'Sensation Red Bartlett' (Dussi et al., 1997). A previous study of EC in the Western Cape showed a contradictory reduction in red colour development in 'Starking' apples, but significant reductions in sunburn in 'Granny Smith' and 'Golden Delicious' apples (Kotze et al., 1988).

The objective of this study was to investigate the efficacy of pulsed applications of evaporative cooling to improve red colour and reduce sunburn on blushed pears in South Africa.

\section{MATERIALS AND METHODS}

\section{0/2001}

Preliminary, semi-commercial experiments were conducted on a 'Rosemarie' orchard at the Welgevallen experimental farm near Stellenbosch $\left(33^{\circ} 58^{\prime} \mathrm{S}, 18^{\circ} 50^{\prime} \mathrm{E}\right)$, Western Cape region, South Africa. The area has a winter rainfall climate with sunny, dry summers and maximum day temperatures commonly exceeding $30^{\circ} \mathrm{C}$.

Two 'Rosemarie' blocks were used: one was established during 1991 on BP1 rootstock at a spacing of $4.5 \mathrm{~m} \times 2 \mathrm{~m}$, the other was established during 1998 on Quince A rootstock at a spacing of $4.0 \mathrm{~m} \times 1.25 \mathrm{~m}$. The EC system consisted of sprinklers installed $7.5 \mathrm{~m}$ apart on $3.8 \mathrm{~m}$ high poles in three alternate rows, with a wetted radius of $3 \mathrm{~m}$. It provided $2 \mathrm{~mm} \mathrm{~h}^{-1}$ irrigation at $200 \mathrm{kPa}$ in a test plot six rows wide and 10 trees long. Control trees were situated in adjacent non-EC rows, well away from the closest sprinkler. From 16 December 2000 (Table 1), the system was activated manually at air temperatures above $25^{\circ} \mathrm{C}$ and continued at cycles of 30 minutes on, 30 minutes off until air temperature decreased below the set point. It was also activated during the late afternoon (18h00) for 30 minutes. Normal undertree micro-irrigation was scheduled according to neutron probe assessments in a part of the orchard that did not receive EC.

On 11 January 2001, 75 fruit were harvested from ten trees in each of three rows per treatment. Hue was measured at the reddest position using a chromameter (NR-3000; Nippon Denshoku, Tokyo, Japan). Presence or absence of sunburn was recorded, and fruit fresh mass was determined.

\section{1/2002}

Statistical trials were established in the same 'Rosemarie' orchard previously used (BP1 rootstock), as well as an adjacent 'Forelle' orchard on Quince A rootstock established in 1998 at a spacing of $4 \mathrm{~m} \times 1.25 \mathrm{~m}$. Pressure compensated DAN 2001 microsprinklers with a $28 \mathrm{~L} \mathrm{~h}^{-1}$ discharge rate and a wetted radius of $1.5 \mathrm{~m}$ were installed in every row at a spacing of $2.5 \mathrm{~m}$ along a suspended pipe $3.5 \mathrm{~m}$ aboveground. The irrigation rate was $\approx 4 \mathrm{~mm} \mathrm{~h}^{-1}$ at $200 \mathrm{kPa}$. Overhead cooling was activated automatically and continued at a cycle of 10 minutes on, 20 minutes off. The activation temperature was $28^{\circ} \mathrm{C}$ from $06 \mathrm{~h} 00$ to $18 \mathrm{~h} 00$ and $20^{\circ} \mathrm{C}$ from $18 \mathrm{~h} 00$ to $21 \mathrm{~h} 00$. A temperature sensor coupled to the irrigation computer was positioned approximately $1.5 \mathrm{~m}$ aboveground in a radiation shield positioned in the adjacent apple orchard. Normal undertree micro-irrigation was provided to all treatments as per usual.

Treatments consisted of a control, an early and a late EC treatment (see Table 1 for starting dates). Treatments were randomised within eight or ten 3-row blocks in the 'Rosemarie' and 'Forelle' orchards, respectively. Only the middle row was used for data collection and adjacent treatments within a row were separated by at least two buffer trees. Sprinklers positioned above control and late EC treatments were plugged using stoppers; these were later removed in the case of the late EC treatment.

Five exposed fruit were marked on the north-western side of three trees per replication. Hue was measured weekly at the reddest position of two fruit per tree using 
the chromameter. All marked fruit were harvested, their hue measured, as well as fruit fresh mass, total soluble solids (TSS, using a refractometer N-1, ATAGO, Japan), and firmness using a penetrometer (FT 327, JR JANISCH, Goodwood, SA). Presence or absence of sunburn was recorded. Fruit were peeled into liquid $\mathrm{N}$ and the peel stored at $80^{\circ} \mathrm{C}$ until pigment analysis by HPLC as described by Steyn et al. (2004). Temperature data was obtained from the Nietvoorbij automatic weather station approximately $4 \mathrm{~km}$ away.

\section{$2002 / 2003$ and $2003 / 2004$}

The trial described above was continued, but the system was activated at $30^{\circ} \mathrm{C}$ from $06 \mathrm{~h} 00$ to $18 \mathrm{~h} 00$ and at $22^{\circ} \mathrm{C}$ from $18 \mathrm{~h} 00$ to $21 \mathrm{~h} 00$. Pulsing continued at a cycle of 5 minutes on, 15 minutes off. During 2002/2003, no late EC treatment was used due to the early harvest date for 'Rosemarie'.

In 2002/2003, fruit skin temperature of 'Forelle' pears was measured in situ using an infra-red thermometer (Raynger MX4, Raytek Corporation, Santa Cruz, CA). Marked fruit were measured on five days during January and February. Fruit under EC treatments were measured when wet. 'Forelle' harvest data for 2003/2004 are not presented due to an erroneous commercial pick one day before the trial harvest which influenced the results.

\section{Statistical Analysis}

The data were analysed by two-way ANOVA using the General Linear Models (GLM) procedure of SAS (SAS release 6.12P; SAS Institute, 1996, Cary, NC) and significance set at $\mathrm{P} \leq 0.05$.

\section{RESULTS AND DISCUSSION}

Results of the preliminary trials $(2000 / 2001)$ indicated that EC could be used to improve the colour of 'Rosemarie' pears, as measured by hue and anthocyanin concentration of the peel (Figs 1A, B). The beneficial effect on hue was more pronounced on Quince A rootstock $(\mathrm{P}=0.0543)$ than on $\mathrm{BP} 1$ rootstock $(\mathrm{P}=0.1492)$. The hue of 'Rosemarie' fruit fluctuated considerably during the 2001/2002 season (Fig. 2A) and to a lesser degree during 2003/2004 (Fig. 2B). Hue was higher (less red) when measured after hot days and lower (redder) when measured after cold nights. During 2001/2002 early EC fruit displayed the same fluctuation in colour as control fruit in response to temperature, but lost less colour during hot periods and were generally redder than control fruit for most of the season (Fig. 2A).

Dussi et al. (1997) found that EC application above $29^{\circ} \mathrm{C}$ reduced the fading of red colour of 'Sensation Red Bartlett' pears in the month before harvest. We previously found that red colour loss in 'Rosemarie' was due to the degradation of anthocyanin and that degradation increased with high temperature (Steyn et al., 2004). EC reduces the peel temperature of apple fruit by up to $8^{\circ} \mathrm{C}$ compared to control fruit (Unrath, 1972; Parchomchuk and Meheriuk, 1996; Wiinsche et al., 2001). A similar EC-induced reduction of up to $6^{\circ} \mathrm{C}$ in the peel temperature of 'Forelle' pears was measured in this trial (data not presented). We assume that the beneficial effect of early EC on pre-harvest 'Rosemarie' fruit colour during 2001/2002 was due to a reduction in fruit temperature during warm days that resulted in a decrease in anthocyanin degradation. This finding was not, however, repeated during 2003/2004 (Fig. 2B); it is unclear why.

Early EC fruit lost red colour during the week before harvest while other fruit became redder in response to colder nights (Fig. 2A). As a consequence, the initial benefit of early EC on colour was lost at harvest, as also shown by the anthocyanin concentrations (Figs. 1A, B, 2A). In contrast, late EC fruit developed more colour during the week before harvest and had significantly lower hue and higher anthocyanin concentration than control fruit at harvest (Figs. 1A, B, 2A). Similarly, during 2003/2004 late EC fruit developed better colour during the last three weeks and were significantly redder at harvest than control or early EC fruit (Fig. 2B). This result on tagged exposed fruit, could not, however, be statistically validated by measurements on a greater number 
of fruit from all canopy positions at harvest (Fig. 1A). During 2002/2003, red blush colour was also improved under $\mathrm{EC}$ treatment although not significantly $(\mathrm{P}=0.0567)$ (Fig. $1 \mathrm{~A})$.

The relative consistency of the results over four seasons suggests that the application of EC from three to two weeks before harvest could be used to improve the colour of 'Rosemarie' pears. However, the beneficial effect of EC was relatively small compared to the weekly fluctuation in 'Rosemarie' colour in response to temperature, indicating that prevailing climatic conditions have a larger effect on colour. The production of 'Rosemarie' in more suitable climatic regions should have a greater beneficial effect on fruit colour than EC.

'Forelle' fruit were initially very red during 2001/2002, but colour gradually faded towards harvest (Fig. 2C). There was little response in hue to seasonal temperature fluctuations or EC. Early EC fruit were slightly redder than control fruit until 4 January 2002, after which the rate of fading of red colour towards harvest was increased relative to other treatments (Fig. 2C, 3A). Hence, the hue of these fruit was higher at harvest than the hue of control and late EC fruit. Only the difference between the two EC treatments was, however, significant. There was no difference in the peel anthocyanin concentration between treatments at harvest (Fig. 2C).

The generally poor responsiveness of 'Forelle' to EC compared to 'Rosemarie' may be attributable to higher anthocyanin concentrations and red colour throughout development (Steyn et al., 2004). High anthocyanin concentrations have a buffering effect on hue, reducing or preventing visible colour change in response to temperature. The stability of 'Forelle' hue in response to high temperature lowers the potential for EC to improve colour. Parchomchuk and Meheriuk (1996) used a similar argument to explain why EC had no effect on the colour of 'Jonagold' apples in a region where night temperatures are generally conducive to anthocyanin synthesis.

Sunburn damage on 'Rosemarie' fruit not receiving EC (control) was exponentially related to the highest daily maximum temperature (Tmax) experienced during the fruit growth period. During 2001/2002 temperatures were very mild (highest Tmax $=33.2^{\circ} \mathrm{C}$ ) and no sunburn occurred. A highest Tmax of $39.1^{\circ} \mathrm{C}$ during $2002 / 2003$ resulted in $13 \%$ sunburn, and a highest Tmax of $40.0^{\circ} \mathrm{C}(2000 / 2001$ and 2003/2004) resulted in $20 \%$ and $31 \%$ sunburn, respectively. The hottest day in 2003/2004 followed a period of unusually low daytime temperatures, and fruit were possibly more sensitised to photodamage.

EC reduced sunburn, although not significantly $(\mathrm{P}=0.1660)$, on trees grafted on Quince A during 2000/2001 (Fig. 1C). There was no reduction in trees grafted on BP1. During 2002/2003 sunburn was slightly but significantly reduced (Fig. 1C; P=0.0412). System failure on the hottest day of the season in 2003/2004 was responsible for the high levels of sunburn recorded on EC-treated fruit (Fig. 1C). Fruit were acclimated to milder conditions and not able to withstand photodamage to the same degree as non-cooled fruit. A similar problem arose during 2002/2003 in the 'Forelle' orchard and EC fruit experienced sunburn levels up to $10 \%$ whereas control fruit had no sunburn (Fig. 3B).

Previous studies have shown that overhead irrigation can effectively control sunburn on apples, although the efficacy may differ between cultivars. Kotze et al. (1988) reported a 50\% reduction in the incidence of sunburn on cooled 'Granny Smith' and 'Golden Delicious' apples. Parchomchuk and Meheriuk (1996) found that evaporative cooling did not reduce the incidence of slight sunburn on 'Jonagold' apples, but did reduce the amount of moderate sunburn. A slightly different form of cooling, namely hydro-cooling, was also effective in reducing sunburn significantly on 'Braeburn' apples (Wiinsche et al. 2001). There is no published information on control of sunburn in pears using EC, but our results indicate that EC may be beneficial in cultivars which are more susceptible, such as 'Rosemarie'. However, it is imperative that the system be highly reliable and sufficient backups are in place in the eventuality of system failure.

During the course of the study, the amount of water used by the EC system was progressively reduced. This was achieved firstly by increasing the set temperature from 
$25^{\circ} \mathrm{C}$ to $28^{\circ} \mathrm{C}$ and then to $30^{\circ} \mathrm{C}$. Secondly, the total pulsing cycle was adjusted from 60 minutes to 30 minutes and then to 20 minutes. Consequently, the additional amount of water entering the soil through EC irrigation was reduced. The soil under EC displayed no evidence of waterlogging at any time, but soil water contents was noticeably higher during the first two seasons (Wand, personal observation). This may explain the initial increases in fruit mass ('Rosemarie' Fig. 1D) and reductions in fruit TSS and firmness ('Rosemarie' Fig. 1E, 1F and 'Forelle' Fig. Fig. 3D, 3E) under the early EC treatment. These effects gradually became less pronounced and no differences were recorded during the final year. In the only previously published EC study on pears (Dussi et al., 1997), fruit firmness also decreased more rapidly under EC than in controls. This was attributed to advanced maturity. However, it was not stated whether undertree irrigation was adjusted, or whether EC provided additional water resulting in higher soil water content. This aspect of EC requires further investigation.

\section{CONCLUSION}

Our results indicate that EC could be used to improve the red colour of 'Rosemarie' pears when applied from about two to three weeks prior to harvest. Since the improvement in colour seemed to be due to a reduction in red colour loss in response to high temperatures, the effect of EC should be greatest in hot production areas. However, the production of 'Rosemarie' in more suitable climatic regions should have a greater beneficial effect on fruit colour than EC. There are no benefits in initiating EC early during fruit development. EC did show promise in reducing levels of sunburn in 'Rosemarie' but this benefit was too inconsistent and small to justify the system only for this application. There are no benefits in the use of EC for 'Forelle' pear fruit quality.

\section{ACKNOWLEDGEMENTS}

This project was funded by the Deciduous Fruit Producers' Trust, the Lombardi Trust, and the National Research Foundation (GUN 2053909). Any opinion, findings and conclusions or recommendations expressed in this material are those of the author(s) and do not necessarily reflect the views of the National Research Foundation. We thank the orchard manager, Marco du Toit, for his co-operation.

\section{Literature Cited}

Bergh, O., Franken, J., van Zyl, E.J., Kloppers, F. and Dempers, A. 1980. Sunburn on apples - preliminary results of an investigation conducted during the 1978/79 season. Decid. Fruit Grow. 30:8-22.

Christie, P.J., Alfenito, M.R. and Walbot, V. 1994. Impact of low-temperature stress on general phenylpropanoid and anthocyanin pathways: Enhancement of transcript abundance and anthocyanin pigmentation in maize seedlings. Planta 194:541-549.

Curry, E.A. 1997. Temperatures for optimal anthocyanin accumulation in apple tissue. J. Hort. Sci. 72:723-729.

Dussi, M.C., Sugar, D., Azarenko, A.N. and Righetti, T.L. 1997. Effects of cooling by over-tree sprinkler irrigation on fruit color and firmness in 'Sensation Red Bartlett' pear. HortTech. 7:55-57.

Evans, R.G., Kroeger, M.W. and Mahan, M.O. 1995. Evaporative cooling of apples by overtree sprinkling. Appl. Eng. Agric. 11:93-99.

Iglesias, I., Salvia, J., Torguet, L. and Cabus, C. 2002. Orchard cooling with overtree sprinkler irrigation to improve fruit colour and quality of 'Topred Delicious' apples. Scientia Hort. 93:39-51.

Kotze, W.A.G., Carreira, J.A., Beukes, O. and Redelinghuys, A.U. 1988. Effect of evaporative cooling on the growth, yield and fruit quality of apples. Decid. Fruit Grow. 38:20-24.

Parchomchuk P. and Meheriuk, M. 1996. Orchard cooling with pulsed overtree irrigation to prevent solar injury and improve fruit quality of 'Jonagold' apples. HortScience 31:802-804. 
Reay, P.F. 1999. The role of low temperatures in the development of the red blush on apple fruit ('Granny Smith'). Scientia Hort. 79:113-119.

Schrader, L.E., Zhang, J. and Duplaga, W.K. 2001. Two types of sunburn in apple caused by high fruit surface (peel) temperature. Online. plant Health Prog. http://www.plantmanagementnetwork.org.

Steyn, W.J., Holcroft, D.M., Wand, S.J.E. and Jacobs, G. 2004. Anthocyanin degradation in detached pome fruit with reference to preharvest red color loss and pigmentation patterns of blushed and fully red pears. J. Amer. Soc. Hort. Sci. 129:13-19.

Unrath, C.R. 1972. The evaporative cooling effects of overtree sprinkler irrigation on 'Red Delicious' apple. J. Amer. Soc. Hort. Sci. 97:55-58.

Unrath, C.R. and Sneed, R.E. 1974. Evaporative cooling of 'Delicious' apples - The economic feasibility of reducing environmental heat stress. J. Amer. Soc. Hort. Sci. 99:372-375.

Wiinsche, J.N., Greer, D.H., Palmer, J.W., Lang, A. and McGhie, T. 2001. Sunburn - the cost of a high light environment. Acta Hort. 557:349-356.

\section{Tables}

Table 1. Timing of beginning of EC treatments and final harvest.

\begin{tabular}{lllr}
\hline & \multicolumn{1}{c}{ Early EC } & \multicolumn{1}{c}{ Late EC } & \multicolumn{1}{c}{ Harvest } \\
\hline 'Rosemarie' & 16 December 2000 & - & 11 January 2001 \\
& 23 November 2001 & 29 December 2001 & 11 January 2002 \\
& 3 December 2002 & - & 5 January 2003 \\
24 November 2003 & 21 December 2003 & 20 January 2004 \\
'Forelle' & 30 November 2001 & 4 February 2002 & 14 February 2002 \\
& 3 December 2002 & 16 January 2003 & 20 February 2003 \\
\hline
\end{tabular}




\section{Figures}
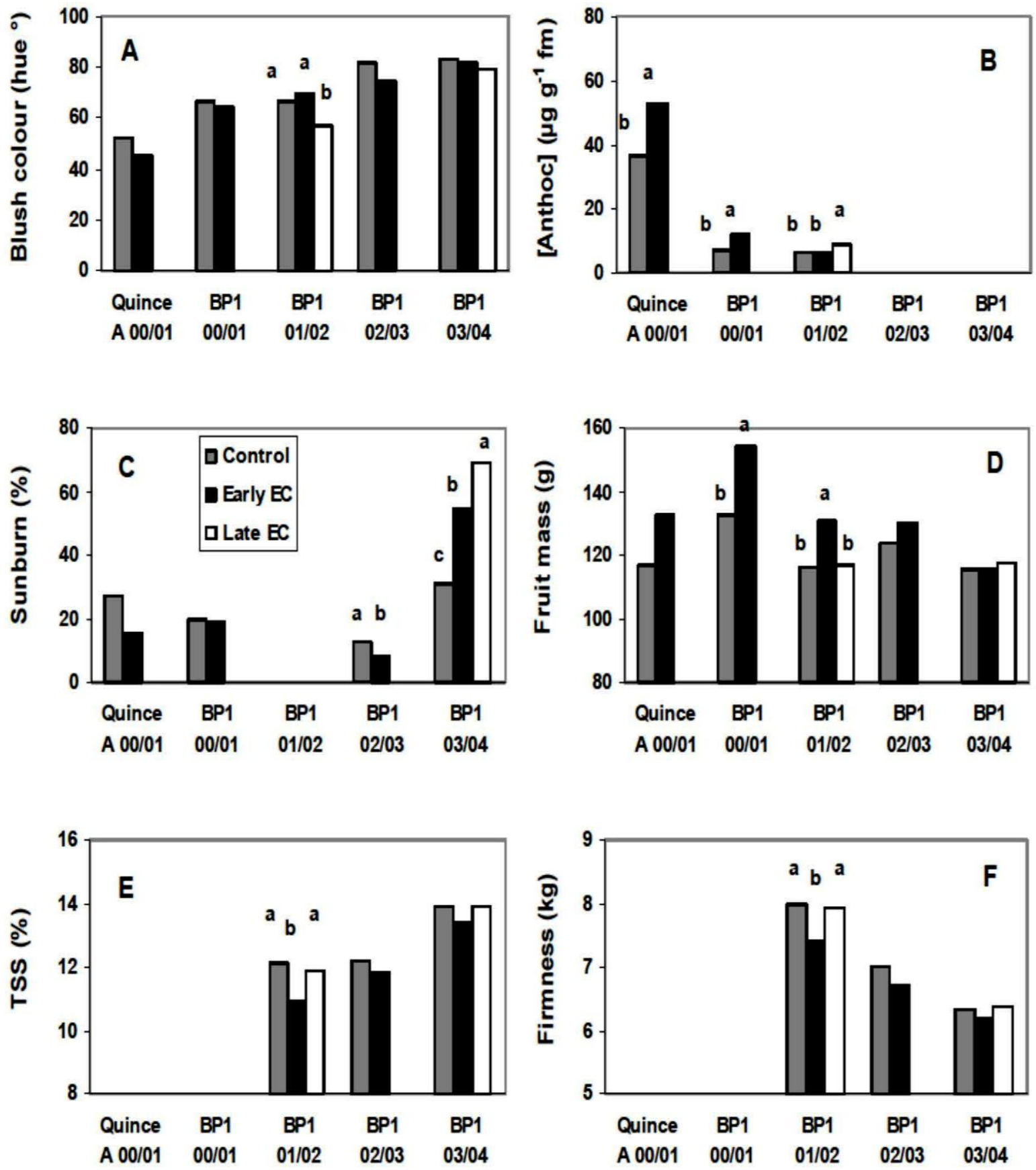

Fig. 1. Quality of 'Rosemarie' pear fruit at harvest in response to early or late EC treatments. 

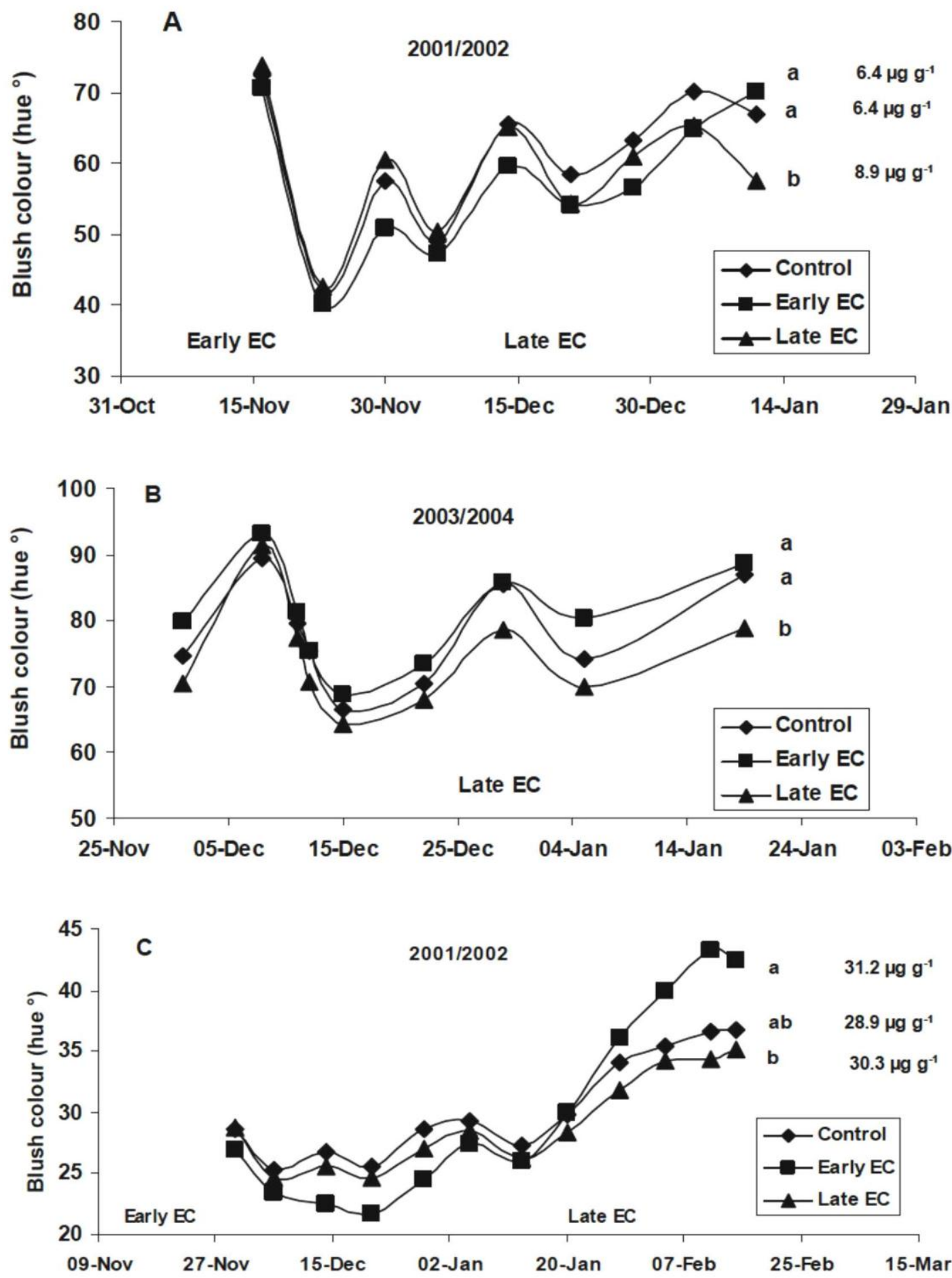

Fig. 2. Seasonal fluctuation in hue for A: 'Rosemarie' 2001/2002, B: 'Rosemarie' 2003/2004, C: 'Forelle' 2001/2002. Peel anthocyanin concentrations are shown for $2001 / 2002$. 

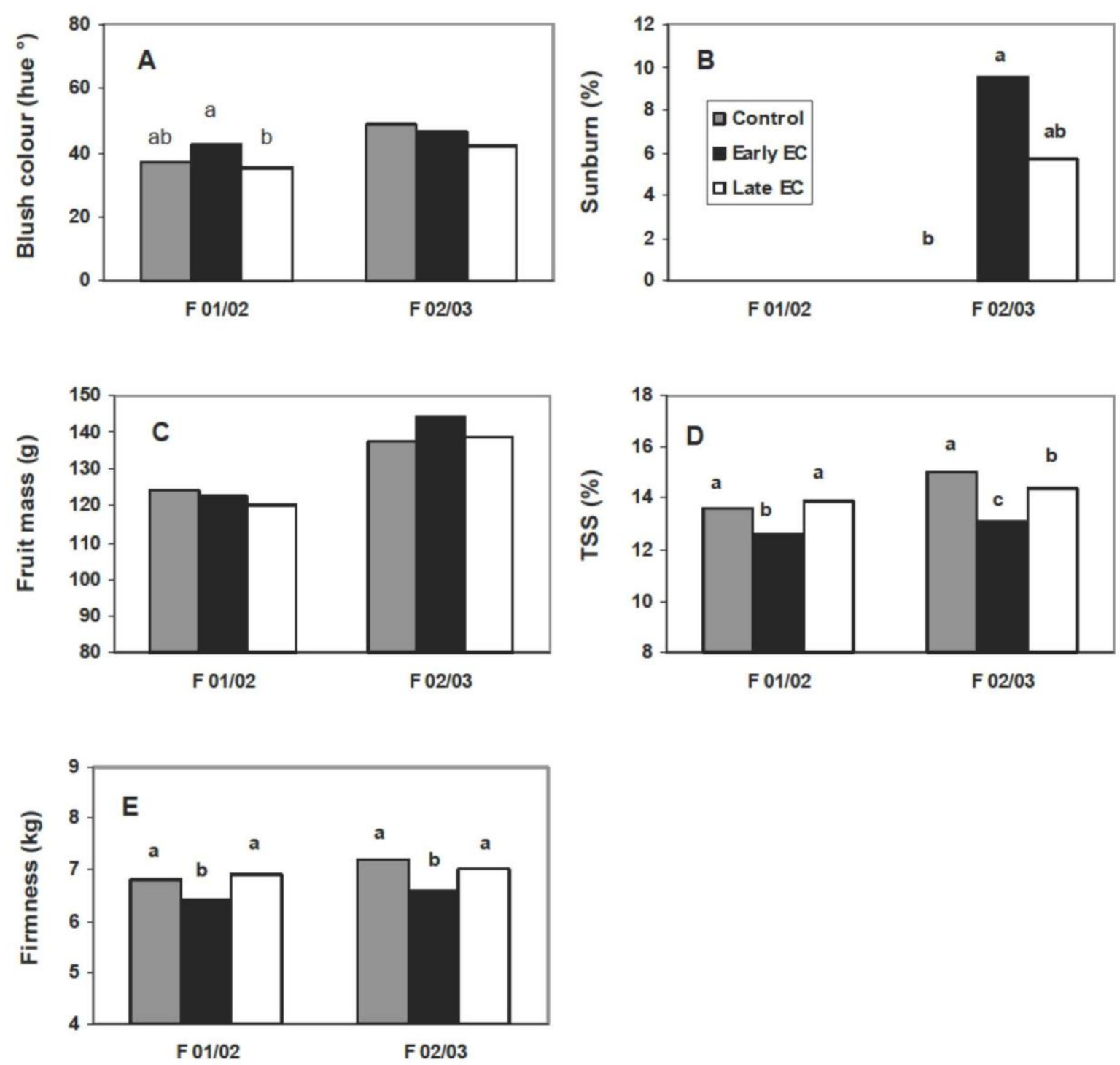

Fig. 3. Quality of 'Forelle' pear fruit at harvest in response to early or late EC treatments. 